\title{
DUODENAL INJURIES
}

\author{
Kirov G., M. Kondarev \\ Medical institute Ministry of Interior, Surgical clinics
}

Reviewed by: Assoc. prof. K. Ivanov, PhD

The injuries of the duodenum are a real challenge to the surgeon based on the anatomophysiological characteristics of the bowel and diagnostic difficulties related to this type of injuries. The delayed diagnosis and treatment failure bring to serious complications and very high mortality (24).

\section{INCIDENCE}

Predominantly retroperitoneal location and relative small length of the duodenum is a reason for the less common involvement in the abdominal trauma. M.A. Levison (19) pointed out, that duodenal lesions are presented at 3-5\% of patients with abdominal injuries. The dominant part of duodenal injuries is penetrating. D.L. Boone (4) emphasize that $75-80 \%$ of these trauma are gunshot related. R.R. Ivatury and all. (14) registered 58 (70,73\%) gunshot injuries in an investigation of a clinical material of 82 patients with penetrating duodenal injuries. J. E.Hasson (12) reports 9 gunshot lesions of duodenum from 10 penetrating abdominal trauma.

\section{CLASSIFICATION}

There are many classifications of the duodenal injuries, but wide popularized and well covered in the surgical literature is the classification of AAST (20). This classification unifies the terminology and gives an opportunity for comparing the treatment results of various surgical centres. Based on this classification, it is possible to build a clear operative tactic (Table 1).

*Advance one grade for multiple injuries up to grade III. D1-first position of duodenum; D2-second portion of duodenum; D3-third portion of duodenum; D4-fourth portion of duodenum From Moore et al. (20)
Despite this classification, which is designed for investigational purpose, in practical aspects the next moments in the duodenal injuries should be taken in consideration $(4,12)$ :

a) involvement of ampulla Vateri

b) partial or full penetration of duodenal wall

c) size of lesion to the circumference

d) concomitant injuries to other organs - pancreas, bile ducts, major vascular vessels;

e) blood loss

f) duration of trauma and severity of peritonitis

\section{DIAGNOSIS}

The diagnosis of the gunshot injuries of the duodenum is made on intraoperative exploration of abdominal cavity. The diagnosis can be supposed preoperatively in cases with entrance wound in upper abdominal half following the trajectory of entrance and exit wounds.

Table 1 Duodenum injury scale

\begin{tabular}{|c|c|l|c||}
\hline \hline Grade* & $\begin{array}{c}\text { Type of } \\
\text { injury }\end{array}$ & \multicolumn{1}{|c|}{ Description of injury } & AIS-90 \\
\hline I & Hematoma & Involving single portion of duodenum & 2 \\
\hline & Laceration & Partial thickness, no perforation & 3 \\
\hline II & Hematoma & Involving more than one portion & 2 \\
\hline & Laceration & Disruption $<50 \%$ of circumference & 4 \\
\hline III & Laceration & Disruption 50\%-75\% of circumference of D2 & 4 \\
\hline & & Disruption 50\%-100\% of circumference of D1,D3,D4 & 4 \\
\hline IV & Laceration & Disruption $>75 \%$ of circumference of D2 & 5 \\
\hline & & Involving ampulla or distal common bile duct & 5 \\
\hline V & Laceration & Massive disruption of duodenopancreatic complex & 5 \\
\hline & Vascular & Devascularization of duodenum & 5 \\
\hline \hline
\end{tabular}
*Advance one grade for multiple injuries up to grade III. D1-first position of duodenum; D2-second
portion of duodenum; D3-third portion of duodenum; D4-fourth portion of duodenum

Address for correspondence:

Kirov G, Medical Institute of the Ministry of Interior, Sofia, BULGARIA
All parts of duodenum should be inspected and attention should be taken on:

1. periduodenal crepitations 
2. periduodenal bile imbibitions

3. retroperitoneal haematoma

The injuries are revealed through mobilisation of entire duodenum. For this purpose a Kocher's mobilisation, opening of bursa omentalis, mobilisation of ligament of Treitzi and the manoeuvre of Catell and Braash are conducted. If the exploration of duodenum is negative, but there is still suspicion of duodenal injuries, Brotman (5) recommends instillation of methylene blue through nasogastric tube. Colouring of the periduodenal tissue is a certain sign for duodenal wall disruption. (5)

In case of retroperitoneal haematoma in upper half of abdominal cavity a control of distal part of inferior caval vein and control of abdominal aorta should be achieved $(2,4,6,15)$.

\section{SURGICAL TACTIC}

About $75-89 \%$ of all duodenal injuries can be treated with relative simple operative procedure. The intramural haematoma formed in zone of cavitation is not indicated for operative treatment. There is a risk of changing a partial thickness wall injury in a full thickness wall injury by the opening and drainage of this type of haematoma and this procedure is not recommended by most authors $(2,17,25)$. A decompressive nasogastric tube is recommended.

The lacerations of duodenum are indicated for primary repair. Various methods are suggested:

- duodenorrhaphy

- duodenorrhaphy with external drainage

- duodenorrhaphy with decompressive internal drainage trough nasogastric tube or jejunostomy

- duodenorrhaphy with internal derivation (jejunogastric anastomosis) without duodenal exclusion and without drainage

- duodenorrhaphy with internal derivation (jejunogastric anastomosis) with internal drainage and without duodenal exclusion

- duodenorrhaphy with internal derivation (jejunogastric anastomosis) with internal drainage and duodenal exclusion

- duodenal diverticulisation - full duodenal discontinuance jejunogastric anastomosis

- closure of the lesion with jejunal anastomosis

- closure of the lesion with jejunal patch

- pancreatoduodenal resection $(2,3,4,6,7,9,10,11,17,18$, 22,25,27)

The choice of the operative method is based on the duration of trauma, severity of peritonitis, localisation and size of laceration.

The most common type of duodenal injuries is indicated for duodenorrhaphy $(2,3,4,6,7,12,13)$. The primary repair is performed with double layer suture in transversal direction to avoid narrowing of the lumen. The transversal closure of the lesion is possible, when its size do not exceed $50 \%$ of the bowel circumference $(4,15,17)$. In the other cases the risk for stenosis is high and closure with jejunal patch or direct anastomosis between the jejunum and duodenal lesion is preferred $(10,21,22)$. The enforcement of suture line with serosal suture of small intestine was promising in experimental condition $(16,26)$ but in clinical circumstances did not show any advantages $(13,22,27)$.

Wide lesions with full disruption of duodenal wall necessitate a mobilisation and debridement of suture line. Primary anastomosis of both ends of duodenum is relative easily made in upper, transversal and ascendant part $(14,15)$. Pars descendens duodeni have a limited possibility for mobilisation due to special vascular pattern, which is related to vascularisation of pancreas. The mobilisation leads to vascular disturbance of duodenal wall and a high risk of anastomotic leak. Wide lacerations in upper part of duodenum are indicated for resection of antrum and duodenum, closure of duodenal stump and gastrojejunal anastomosis - Billroth II. The bigger lesions under the ampula Vateri are repaired with closure of distal end of duodenum and anastomosis of proximal end with a jejunal lop or Roux Y anastomosis (22).

Pancreatoduodenal resection is a method with high mortality in emergency trauma condition $(1,18,23)$. It is indicated as two-stage procedure at severe injuries of the duodenopancretic complex - IV and V grade $(6,8,9,11,17)$. On the first stage a control of bleeding and contamination is conducted by debridement, ligation of common bile duct and pancreatic duct. The reconstruction is performed after 48 hours and good resuscitation of wounded (17).

The primary duodenal repair has a significant risk for suture leak and development of duodenal fistula. This risk rises in severe abdominal trauma and advanced peritonitis. Various operative techniques of duodenal decompression and external drainage are performed for prevention or local control of insufficiency and fistulisation. The external drainage is strongly recommended, because it makes possible the early detection and the good control of the leak $(3,4,12,14,22,23)$. The retrograde tube decompression trough jejunostomy in duodenal trauma is first described by Stone and Garoni as part of triple catheterstomy - gastrostomy and jejunostomy. Through the afferent loop of jejunostomy is performed the retrograde duodenal decompression, through the efferent loop a feeding tube is inserted for an early enteral nutrition. The initial hopeful results of these techniques for lowering the rate of anastomotic leak are not confirmed by more recent studies $(7,15)$.

The first duodenal exclusions were performed trough diverticulisation of duodenum - distal resection of stomach, closure of duodenal stump and gastrojejunal anastomosis. This is a Billroth II resection in essence and is not recommended at haemodynamicaly unstable patients and in absence of lesions in pyloroantral zone.

The pyloric closure with hand or stapler suture or ligation by Tomoda is imposed as an alternative to the diverticulisation. The pyloric exclusion is technically easer, less radical and shorter operation than the diverticulisation and posses the same effect to the protection of duodenal suture $(2,3,4,25)$. In generally, the most authors indicate lower incidence of suture insufficiencies by using the techniques of duodenal decompression. The primary repairs without 
decompression are associated with $19,4 \%$ rate of duodenal fistula, while this rate by decompression is $2,3 \%$ (12).

The surgical tactics in gunshot injuries of duodenum can be generalized according to classification of AAST to the following steps:

I grade - nonoperative, seromuscular suture

II grade - primary suture with drainage

III grade - primary suture or resection with pyloric closure

IV and V grade - pancreatoduodenal resection

\section{MORTALITY AND MORBIDITY}

The gunshot injuries of the duodenum are characterized with a significant morbidity and mortality. The prostoperative complications vary between $38 \%$ and $100 \%$. Most commonly are the duodenal fistulas, stenosis of duodenum and high ileus, intraabdominal infections, pancreatitis and biliary fistulas $(1,2,4,12,14,19,27)$.

The mortality according to various reports ranges from 5,3 to $73 \%(2,4)$. The high mortality in the early postoperative period is related to the massive exsanguination due to injuries of major vascular vessels. The late mortality is caused by septic complications.

\section{REFERENCE}

1. Amirata E, Livingston DH, Elcavage J.: Octreotide acetate Decreases pancreatic complications after pancreatic trauma. Am J. Surg 1994; 168:345

2. Asensio J.A, Demetriades D, Berne J.D, Falabella A, Gomez H, MarrayJ. etal. A unified approach to surgical exposure of pancreatic and duodenal injuries. Am Surg 1997; 174: 54-60.

3. Asensio J.A, Feliciano DV, Britt LD, Kerstein MD. Management of duodenal injuries. Curr Probl Surg 1993; 30: 1023-92.

4. Boone DC, Peitzman AB. Abdominal injury-duodenum and pancreas. In: Peitzman AB, Rhodes M, Schwab SW, Wealy DM, eds. The Trauma Manual. Philadelphia, Pennsylvania: Lippincott-Raven, 1998: 242-7.

5. Brotman S, Cistemino S, Myers RA, Cowley RA. A test to help diagnosis of rupture in the injured duodenum. Injury 1981; 12: 464-5.

6. Carrillo EH, Richardson J.D, Miller FB. Evolution in the management of duodenal injuries. J. Trauma 1996; 40: 1037-46.

7. Cogbill TH, Moore EE, Feliciano DV, Hoyt DB, Jurkovich GJ., Morris J.A etal. Conservative management of duodenal trauma: a multicenter perspective. J. Trauma 1990; 30: 1469-75.

8. Degiannis E, Levy RD, Velmahos GC, Potokar T, Florizoone MG, Saadia R. Gunshot injuries of the head of the pancreas: conservative approach. World J. Surg 1996; 20: 68-72.

9. Degiannis E, Saadia R. Controversies in management of penetrating injuries of the pancreas. S.Afr.J.. Surg 1999; 37: 38-40.

10. DeShazo CV, Snyder WH, Daugherty CG, Crenshaw CA. Mucosal pedicle graft of jejunum for large gastrointestinal defects. Am J. Surg 1972; 124: 671-2.
11. Feliciano DV, Martin TD, Cruse PA, Graham J.M, Burch J.M, Mattox KL etal. Management of combined pancreatoduodenal injuries. Ann Surg 1987; 205: 673-80.

12. Hasson J.E, Stern D, Moss GS. Penetrating duodenal trauma. J. Trauma. 1984; 24(6):471-4.

13. Ivatury RR, Gaudino J., Ascer E, Nallathambi M, Ramirez Schon G, Stahl WM. Treatment of penetrating duodenal injuries: primary repair vs. repair with decompressive enterostomy/serosal patch. J. Trauma 1985; 25: 337-41.

14. Ivatury RR, Nallathambi MN, Gaudino), Rohman M, Stahl WM. Penetrating duodenal injuries. Analysis of 100 consecutive cases. Ann Surg 1985; 202: 153-8.

15. Ivatury RR, Nassoura ZE, Simon RJ., Rodruigez A. Complex duodenal injuries. Surg Clin North Am 1996; 76: 797-812.

16. Jones SA, Gazzaniga AB, Keller TB. The serosal patch. A surgical parachute. Am J.Surg 1973; 126: $186-96$.

17. Kauder DR, Schwab CW, Rotondo MF. Damage control. In: Ivantury RR, Cayten CG, eds. The Textbook of Penetrating Trauma. Baltimore, Maryland: Williams and Wilkins, 1996: 717-25.

18. Konairis LG, Mandal AK, Genuit T, Cameron J.L: Two-stage trauma pancreaticoduodenectomy: delay facilitates anastomotic reconstruction. J. Gastrointest Surg 2000; 4(4):366-9

19. Levison MA, Petersen SR, Sheldon GF, Trunkey DD. Duodenal trauma: experience of a trauma center. J. Trauma. 1984;24(6):475-80.

20. Madjov R.,Arnaudov P., Diagnostic and therapeutic strategy in patients with abdominal and thoracoabdominal trauma. Surgery $(B G), 200157$ (5-6): 14-18

21 Moore EE, Cogbill TH, Malangoni MA. Organ injury scaling, II: Pancreas, duodenum, small bowel, colon and rectum. J. Trauma 1990; 30: 1427-1429

22. Papachristou DN, Former J.G. Reconstruction of duodenal wall defects by the use of a gastric 'island' flap. Arch Surg 1977(2): 112: 199-200.

23. Purtill M-A, Stabile BE. Duodenal and pancreatic trauma. In: Naude GP, Bongard FS, Demetriades D, eds. Trauma Secrets. Philadelphia, Pennsylvania: Hanley and Belfus, 1999: 123-30.

24. Shilyansky J., Pearl RH, Kreller M, Sena LM, Babyn PS. Diagnosis and management of duodenal injuries in children. J.PediatrSurg 1997; 32: 880-6.

25. Timaran CH, Martinez O, Ospina J.A. Prognostic factors and management of civilian penetrating duodenal trauma. J. Trauma 1999; 47: ^0-5.

26. Velmahos GC, Kamel E, Chan LS, Hanpeter D, Asensio J.A, Murray J.A etal. Complex repair for the management of duodenal injuries. Am Surg 1999; 65: 972-5.

27. Walley BD, Goco I. Duodenal patch grafting. AmJ.Surg 1980; 140: 706-8.

28. Wynn M, Hill DM, Miller DR, Waxman K, Eisner ME, Gazzaniga AB. Management of pancreatic and duodenal trauma. Am J. Surg 1985; 150:327-32. 